\title{
High-grade glioma mimicking acute viral encephalitis - three case reports
}

\author{
J H Rees, R S Howard
}

\begin{abstract}
Summary
The clinical features of viral encephalitis consist of headache, fever, seizures and encephalopathy. We report three patients with high-grade gliomas presenting with encephalitic illnesses. The diagnosis of brain tumour should always be borne in mind if definite evidence for a viral infection is not obtained.
\end{abstract}

Keywords: glioma; viral encephalitis; encephalopathy

Viral encephalitis is characterised by headache, confusion, altered consciousness with or without seizures, and fever. The most commonly identified cause of sporadic communityacquired encephalitis is herpes simplex virus (HSV) type I, which may be diagnosed on viral culture of cerebrospinal fluid (CSF), polymerase chain reaction (PCR) analysis looking for HSV DNA, serological testing for IgM antibodies, or brain biopsy. Characteristically the virus attacks the medial temporal lobes and insular cortex giving rise to a focal encephalitis which carries a significant mortality rate. ${ }^{1}$ Rarely, the patient presents with symptoms and signs of raised intracranial pressure, giving rise to the possibility of a temporal lobe abscess. The converse situation, whereby a high-grade tumour presents as an acute encephalitic illness, has only rarely been reported. The following three cases illustrate that this diagnosis should always be borne in mind if definite evidence for a viral infection causing the encephalopathy is not obtained, especially if the PCR test is negative for the presence of viral DNA.

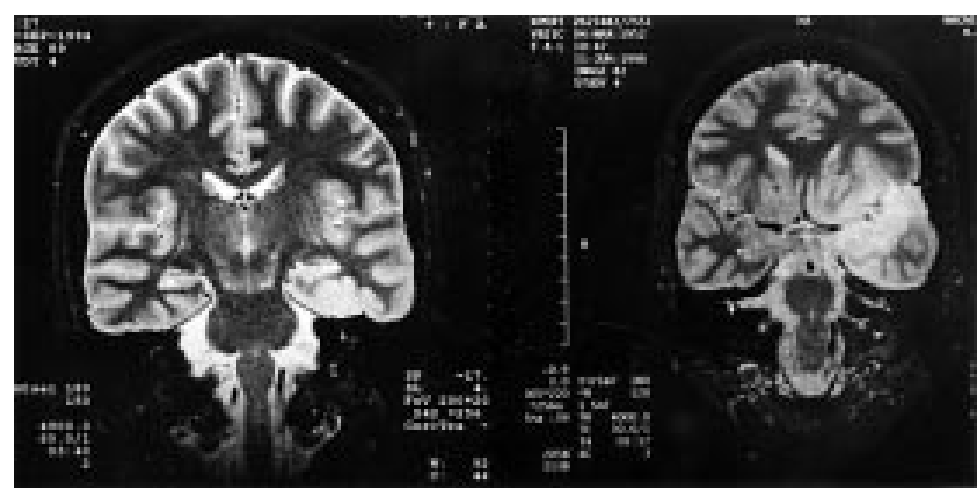

Figure 1 Coronal T2-weighted MRI scans showing an area of high signal in the left medial temporal lobe which was identical to the images on presentation 2 years earlier. Two years later and one month before the patient's death, the abnormality is more extensive and involves the inferior parietal lobe

\section{Case reports}

\section{Case 1}

A 41-year-old woman presented with tonicclonic seizures, fever, drowsiness and confusion. Magnetic resonance imaging (MRI) showed extensive high signal abnormality in the left temporal lobe and posterior parietal region (figure 1). CSF was normal. A presumptive diagnosis of herpes simplex encephalitis (HSE) was made and she improved after intravenous acyclovir. However, her seizures persisted and 2 years later her MRI scan showed an increase in the size of the temporal lesion (figure 1). Approximately one month later, she was found unconscious at home. A CT scan now showed a large lesion with considerable midline shift. Emergency decompression was unsuccessful and she died without regaining consciousness. The histology of the lesion was glioblastoma multiforme.

\section{Case 2}

A 49-year-old man became acutely confused and then had serial tonic-clonic seizures. On admission he was pyrexial, tachycardic and unconscious. MRI showed extensive high T2 signal change affecting the right temporal and frontal lobes with some mass effect (figure 2). CSF examination including PCR for HSV DNA was negative. He was started on acyclovir and gradually improved. He had persistent simple partial seizures and a repeat MRI 3 weeks later showed no change. A stereotactic brain biopsy was carried out and revealed an anaplastic astrocytoma. He was treated with external beam radiotherapy followed by combination chemotherapy.

\section{Case 3}

A 72 -year-old woman presented with a 2 -week history of episodes of vagueness and confusion. MRI revealed a lesion involving the grey and white matter of the left temporal lobe but also a similar process involving the right temporal lobe and uncus (figure 3). There was some mass effect and mild contrast enhancement. It was felt that the appearances were more consistent with HSE than glioma. A CSF sample taken 5 days after starting acyclovir was normal, including PCR for HSV DNA. She remained persistently confused with frequent simple and complex partial seizures. One month later MR guided stereotactic biopsy of the left temporal lobe revealed a high-grade astrocytoma which was not treated at the request of her family. 


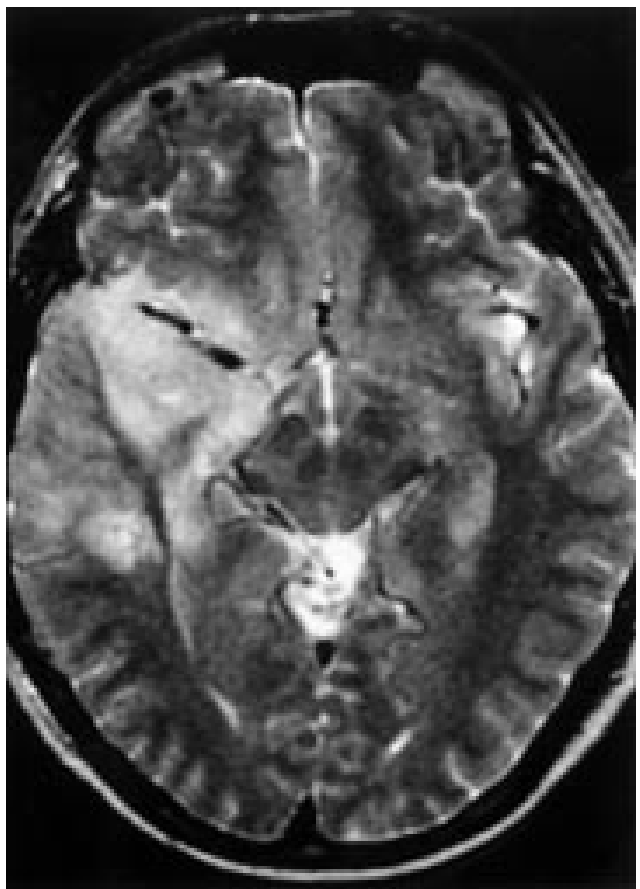

Figure 2 Axial T2-weighted MRI scan showing diffuse high signal change in the right anterior temporal lobe with a second smaller focus more posteriorly

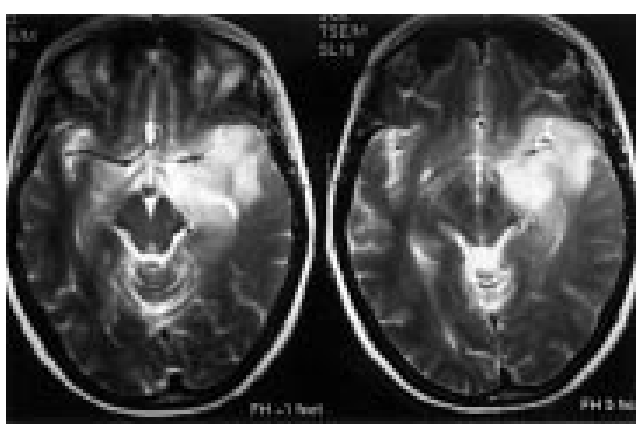

Figure 3 Axial T2-weighted MRI scan showing extensive left medial temporal high signal with some abnormality also seen medially in the right temporal lobe

\section{Discussion}

All three patients described above presented acutely with confusion and seizures. Fever was present in the first two cases and all patients had extensive areas of high signal on T2-weighted MR imaging within one or both (Case 3) temporal lobes. HSE was therefore diagnosed on both clinical and radiological grounds. Results of CSF examination were normal in each case, but as this was not incompatible with HSE, the patients were treated with a full course of intravenous acyclovir. No patient received steroids at presentation and the improvement in patients 1 and 2 presumably occurred as a consequence of achieving seizure control. It was only when the results of the PCR came back as negative that the initial diagnosis was reconsidered. In cases 2 and 3 a high-grade temporal lobe glioma was diagnosed using CT or

\section{Learning points}

- a malignant brain tumour can present acutely as fever and encephalopathy with bilateral abnormalities on MRI scanning

- stereotactic biopsy should be considered in patients with temporal lobe mass lesions if no definitive diagnosis is made after the results of PCR analysis for common viruses are available

MR-guided stereotactic biopsy within one to two months of the original presentation. The first patient, however, remained undiagnosed for over 2 years and biopsy was not carried out principally because the MRI scan appearances of the lesion had not obviously changed. Her final MRI scan showed that the tumour had increased in size but the decision to biopsy electively was never made as she presented soon after in extremis. Presumably the tumour had undergone transformation from low-grade to high-grade in a short space of time.

The distinction between acute viral encephalitis and a glioma is usually easily made on clinical and radiological grounds. PCR can be used to identify viral DNA in the CSF and allows early diagnosis of $\mathrm{HSE}^{2}$ Occasionally the presentation is atypical and HSE may mimic a rapidly expanding temporal lobe mass, giving rise to considerable diagnostic difficulty. ${ }^{3-5}$ However, the converse situation whereby a malignant glioma presents as an acute encephalopathy is much rarer.

This 'encephalitic' presentation of temporal lobe tumours has been previously alluded to in a study of 432 patients who underwent brain biopsy for presumed HSE, in the pre-MRI era. ${ }^{6}$ Five out of $95(6 \%)$ patients who were biopsynegative for HSE had tumours, two metastatic colonic adenocarcinomas, one primary CNS lymphoma and two glioblastomas. In another study looking at the differential diagnosis and outcome of 65 patients presenting with an acute encephalopathy over a 17-year period, only one patient out of 34 in whom a definite or probable diagnosis could be made had a tumour. This was a 45-year-old man presenting with a short history of headache and confusion who had a right temporal lobe lesion. Three years later a biopsy revealed an oligodendroglioma. ${ }^{7}$

This very low frequency suggests that a primary CNS tumour rarely presents as an encephalitic illness. With the advent of PCR analysis brain biopsy is seldom undertaken to diagnose HSE, particularly as the most common differential diagnoses include other viral encephalitides for which no specific treatment is currently available. However, we believe that stereotactic biopsy should be considered in all patients with temporal lobe mass lesions if no definitive diagnosis is made after the results of PCR analysis for common viruses are available. This is because the procedure carries very little risk and other potentially treatable conditions such as bacterial abscesses, fungal infections and tuberculosis would otherwise be missed. 
1 Whitley RJ. Viral encephalitis. N Engl f Med 1990;323:242 50

2 Aurelius E, Johansson B, Skoldenberg B, Staland A Forsgren M. Rapid diagnosis of herpes simplex encephalitis by nested polymerase chain reaction assay of cerebrospina fluid. Lancet 1991;337:189-92.

3 Page LK, Tyler R, Shillito J. Neurosurgical experiences with herpes simplex encephalitis. F Neurosurg 1967;27:346-52.

4 Feldman RA, Shende MC. Herpes simplex virus encephalitis simulating a frontoparietal convexity neoplasm. Surg Neurol 1975;3:329-32.
5 Hume Adams J, Bryan Jennett W. Acute necrotising encephalitis: a problem in diagnosis. $\mathcal{F}$ Neurol Neurosurg Psychiatry 1967;30:248-60.

6 Whitley RJ, Glenn Cobbs C, Alford CA, et al. Diseases that mimic herpes simplex encephalitis. $\mathcal{F} A M A$ 1989;262:234-9.

7 Ginsberg L, Compston DAS. Acute encephalopathy: diagnosis and outcome in patients at a regional neurological unit. $O f M e d 1991 ; 87: 169-80$.

\title{
Hypertensive encephalopathy in a patient with retroperitoneal fibrosis
}

\author{
D Das, J Brigg, C M Brown
}

\begin{abstract}
Summary
A patient presented with retroperitoneal fibrosis but without any ureteric obstruction. The diagnosis was made by an abdominal CT scan and also at laparotomy. Post-operatively, she developed hypertensive encephalopathy. An isotope renogram with captopril was abnormal but not diagnostic of renal artery stenosis. The patient's condition improved with steroid and antihypertensive treatment. A follow-up CT scan showed complete resolution of peri-aortic thickening. A causative link is postulated between retroperitoneal fibrosis, trauma during laparotmy, and onset of acute hypertension.
\end{abstract}

Keywords: retroperitoneal fibrosis; hypertensive encephalopathy

Retroperitoneal fibrosis, first described by Ormond in 1948, characteristically affects the peri-aortic tissues often involving the ureters, leading to ureteric obstruction. The pathogenesis of this disease, though not fully understood, is now recognised to be immune mediated. Although no therapeutic trials have been conducted because of low incidence of the disease, steroid treatment has been found to be effective in most cases. Patients often present with non-specific symptoms and occurrence of hypertension has been rarely reported in these patients. The present case report is related to a patient with retroperitoneal fibrosis complicated by hypertensive encephalopathy, the first case report of its kind. We discuss the possibility of a causal relationship between these two conditions and the role of steroid treatment in preventing such complications.

\section{Case report}

Correspondence to Dr D Das, Consultant Physician, Stepping Hill Hospital, Stockport, SK2 7JE, UK 50-year-old woman presented 3-month history of anorexia and weight loss of $14 \mathrm{lbs}$. She had undergone hysterectomy and bilateral salpingo-oophorectomy several years

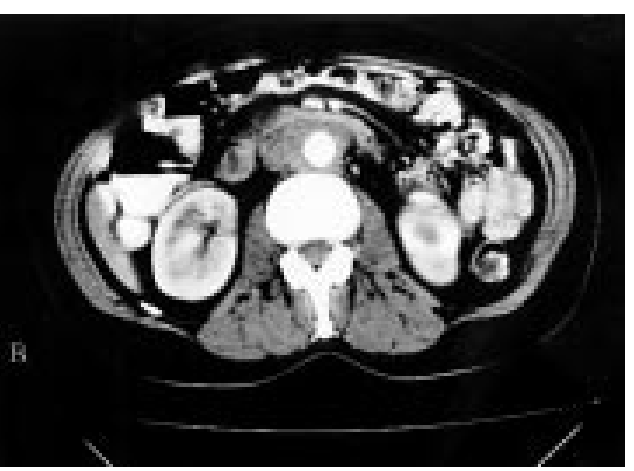

Figure 1 Post-contrast CT scan of the abdomen showing thickening of the aortic wall due to extensive fibrosis

earlier and was subsequently put on hormone replacement therapy. She specifically denied previous exposure to ergot, methysergide or practolol. Blood pressure, fundoscopy and a resting electrocardiogram (ECG) were all found to be normal at initial screening. On abdominal palpation, a para-umbilical mass was noted but without any evidence for hepatosplenomegaly or ascites. Full blood count and electrolytes were normal but erythrocyte sedimentation rate (ESR) was raised to $94 \mathrm{~mm} / \mathrm{h}$. Auto-immune screen for antibodies was negative and immunoglobulin levels were normal. Abdominal computed tomography (CT) scan showed a fairly well defined cuff of tissue surrounding the aorta from the level of the renal vessels to the distal common iliac arteries on both sides of the pelvis with no abnormality of the other intra-abdominal organs (figure 1).

A laparotomy was performed to exclude lymphoma but extensive thickening of the aorta, superior mesenteric, renal and common iliac arteries was noted. Histology of a cuff of tissue dissected from the peri-aortic region showed predominantly fibrous tissue infiltrated with plasma cells and lymphocytes, the latter often aggregated in places in the form of follicles. 


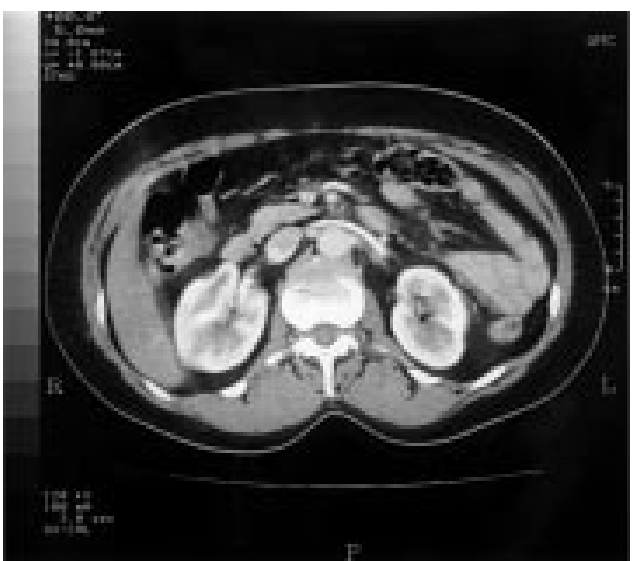

Figure 2 Post-contrast CT scan of the abdomen, 1 year after institution of steroid treatment, showing resolution of inflammatory oedema and fibrosis around the aorta.

On the second postoperative day her blood pressure progressively rose to $230 / 120 \mathrm{mmHg}$, precipitating a generalised convulsion. CT scan of the brain demonstrated oedema over the vertex region with effacement of the cortical sulci but no haemorrhage. The total volume of intravenous fluid replacement in the postoperative period was only 2 litres. 24-Hour urinary catecholamine levels were normal. Systemic blood pressure was controlled with $50 \mathrm{mg}$ intravenous labetalol followed by oral prednisolone $(40 \mathrm{mg})$ and bendrofluazide (2.5 $\mathrm{mg}$ daily). An isotope renogram showed no initial abnormality but reduced bilateral renal function following a single dose of captopril. The classical delay in clearance, associated with renal artery stenosis, was not noted. More than a year after discharge from the hospital the patient remains well with normal blood pressure and an ESR of $5 \mathrm{~mm} / \mathrm{h}$. A repeat CT of the abdomen (figure 2) showed resolution of the

1 Weatherall DJ, Ledingham JGG, Warrell DA. Oxford Textbook of medicine, 3rd edn. Oxford: Oxford University Press, 1996, pp 3243-7. inflammatory oedema and fibrosis around the aorta, seen in the previous CT. Her current treatment comprise atenolol $50 \mathrm{mg}$, nifedipine $20 \mathrm{mg}$ and prednisolone $5 \mathrm{mg}$.

\section{Discussion}

The clinical condition of retroperitoneal fibrosis, presenting as ureteric obstruction and perianeurysmal thickening of the aortic wall has long been recognised, but wider use of CT scanning detects more asymptomatic cases. This condition is thought to be secondary to leakage of material from atheromatous plaque in the diseased aorta, generating an autoimmune inflammatory response ${ }^{1}$ and the presenting symptoms depend on the organs or vascular structures involved.

Mild hypertension has been previously reported with this condition, ${ }^{2}$ but no studies have been carried out to determine a causal relationship. However, hypertensive encephalopathy, manifest by cerebral oedema and a generalised convulsion has not been previously reported. The precise reason for severe hypertension in this woman is subject to speculation, but may involve inflammatory narrowing of the renal arteries, as evidenced by the abnormal post-captopril isotope renogram, with further local tissue oedema resulting from retroperitoneal biopsy at laparotomy. Steroid treatment may have controlled the inflammation improving the patency of the renal arteries. Our patient improved with steroids and antihypertensive therapy and could not be persuaded to undergo renal angiography.

This is the first case report documenting occurrence of hypertensive encephalopathy following operative biopsy in a patient with retroperitoneal fibrosis. The possibility of such a complication should prompt consideration of steroid treatment before invasive procedures or laparotomy is undertaken.

2 Anon. A 31-year-old woman with lumbar and abdominal pain, hypertension, and a retroperitoneal mass (Case records of Massachusetts General Hospital). $N$ Engl f Med 1996;335:650-5. 


\title{
Visceral leishmaniasis masquerading as tuberculosis in a patient with AIDS
}

\author{
Amitabh Yaduvanshi, Meenakshi Jain, S K Jain, Shyama Jain, Suneet Arora
}

\begin{abstract}
Summary
We report a case of visceral leishmaniasis presenting as significant lymphadenopathy in a patient with acquired immune deficiency syndrome. The lymphadenopathy was initially suspected to be tubercular in nature on pathological examination. This report highlights the increasing incidence of acquired immune deficiency syndrome and Leishmania co-infection in India, and the importance of demonstrating tubercle bacilli on culture before suggesting a diagnosis of tuberculosis.
\end{abstract}

Keywords: leishmaniasis; AIDS; tuberculosis

Visceral leishmaniasis (VL) is being increasingly recognized in human immunodeficiency virus / acquired immune deficiency syndrome (HIV/AIDS) patients. ${ }^{12}$ It occurs in epidemic form in Eastern India. Given the endemicity of VL in this area, physicians can expect to see VL in patients with HIV/AIDS. Resistance to sodium antimony gluconate, the paucity of alternative drugs such as pentamidine and amphotericin B, and woefully inadequate vector control measures in VL, make the situation positively explosive in developing countries. To the best of our knowledge there are only two case reports of HIV and VL co-infection from India, but this is the first report in which the patient presented with predominant lymphadenopathy, with no suspicion of HIV or leishmaniasis.

\section{Case report}

A 30-year-old man from Eastern Uttar Pradesh (in the VL belt in India) presented with moderate-grade intermittent fever associated with chills for the last 7 months. He also complained of swelling in the neck, axillary and inguinal regions for the past 6 months, and associated complaints of anorexia, weight loss and malaise. He had no other symptoms. He had undergone surgery for varicose vein removal 8 years earlier, during which he had received multiple units of blood. There was no history of any other high-risk behaviour.

He had been treated for tuberculosis for the past 6 months based on an inguinal lymph node fine needle aspiration cytology (FNAC) diagnosis of granulomatous lymphadenitis, possibly of tubercular nature. The patient was started on antitubercular drugs (rifampicin, isoniazid, ethambutol, pyrazinamide) reduced to two drugs after three months (RH). However there was no improvement in the patient's symptomatology.

Physical examination revealed generalised lymphadenopathy of $2-3 \mathrm{~cm}$ in size, firm, nontender and non-matted. Pallor, cachexia, herpes simplex labialis and oral thrush were present along with a $3-\mathrm{cm}$ hepatomegaly and a $5-\mathrm{cm}$ splenomegaly. The rest of the systemic examination was normal.

Investigation revealed haemoglobin $8.7 \mathrm{~g} / \mathrm{dl}$, total leucocyte count $3200 / \mu 1$ with $70 \%$ polymorphs and $30 \%$ lymphocytes, platelets $99 \times 10 \mathrm{~g} / \mathrm{l}$, erythrocyte sedimentation rate $75 \mathrm{~mm} / 1 \mathrm{st}$ hour. Other investigations were within normal limits. Ultrasonographic examination revealed hepatosplenomegaly with abdominal lymphadenopathy.

A review of the previous FNAC revealed non-caseating granuloma (figure 1); acid-fast bacilli (AFB) staining was not done. At the same time lymph node biopsy from axillary lymph nodes showed non-specific dermatopathic changes. Mantoux test and ELISA for tuberculosis IgG and IgA were within normal limits. Bone marrow aspirations did not reveal any haemoparasites.

ELISA for HIV was positive and later confirmed by Western blot technique. Repeat FNAC from inguinal lymph node revealed numerous intracellular and extracellular amastigote forms of Leishmania donovani (LD bodies) (figure 2). The CD4 count (helper/ inducer) was $2 \%$ and absolute CD 4 count was $30 / \mu 1$.

A final diagnosis of AIDS stage IVC with VL (kala azar) was made. The antitubercular drugs were withdrawn and the patient was started on intramuscular (im) sodium stibogluconate (20 $\mathrm{mg} / \mathrm{kg}$ body weight/day), continued for 28

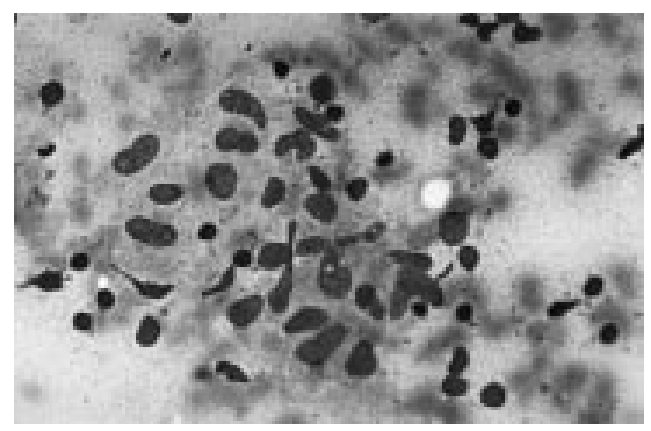

Figure 1 First FNAC smear from inguinal lymph node showing non-caseating epithelioid cell granuloma 


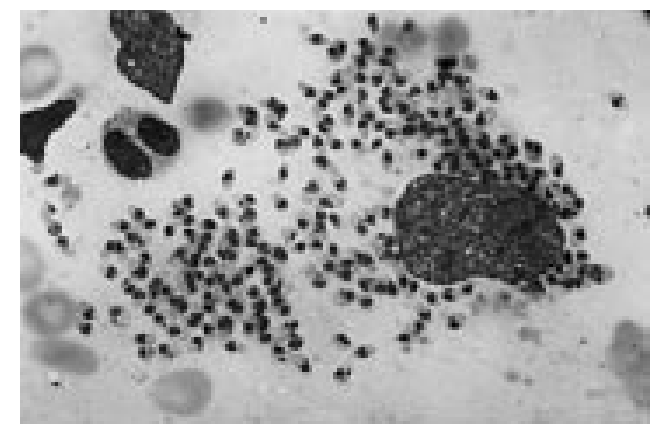

Figure 2 Second FNAC smear from inguinal lymph node showing LD bodies

days. The patient responded well to the treatment and showed an improvement in general condition; his lymph nodes had regressed appreciably by the end of therapy. He was discharged on prophylaxis for tuberculosis and Pneumocystis carinii. Repeat lymph node FNAC and bone marrow aspiration did not reveal any LD bodies after 3 months. His fever had completely subsided and there was marked regression of splenomegaly. He was continued on im sodium stibogluconate, once a month, for prophylaxis against relapse of VL.

\section{Discussion}

The case has certain unique features. It is the third case of HIV/VL co-infection reported from India. The patient had lymphadenopathy as the predominant presentation, which is uncommon in Indian VL, and the lymphadenopathy had previously been misdiagnosed as tubercular in origin.

Tuberculosis is highly prevalent in India and is a common cause of lymphadenopathy. Due to lack of resources, the patient is usually started on antitubercular drugs on the basis of the cytohistological appearance, without resorting to AFB staining or culture. This strategy is generally helpful, as other granulomatous diseases are uncommon in India. However, lymphadenopathy and granuloma formation are rarely seen in VL. In response to the initial infection there is a migration of histiocytes into the lymph nodes, resulting in the formation of non-caseating granuloma. These granulomas may sometimes be thought to be tubercular in origin due to the paucity of LD bodies in the early stages, as happened in our patient. There is then reactivation of this latent infection when the patient is stressed or immunocompromised in any way. At this stage the granuloma and histocytes are disrupted and numerous LD bodies are seen on cytology or histology, as was the case in our patient whose repeat FNAC showed numerous LD bodies.

In a recent WHO communication, 692 retrospective cases of $\mathrm{HIV} / \mathrm{VL}$ co-infection were reported; $97.3 \%$ of these cases originated from Southern Europe. ${ }^{12}$ However, this is only the third case of HIV/VL co-infection reported from India. ${ }^{34}$ The possible reasons for the scarcity of cases from India are, firstly, that the

\section{Learning points}

- clinicians in developing countries should be aware of co-infection of HIV and VL

- VL can rarely present as lymphadenopathy

- the initial response to leishmanial infection may be in the form of non-caseating granuloma formation

- caseating/non-caseating granulomas should be stained for AFB before a diagnosis of tuberculosis is made, and the diagnosis should be revised if the patient does not show clinical improvement after 3 months of anti-tubercular therapy

- non-specific dermatopathic changes in lymph-node biopsy are also features of AIDS-related lymphadenopathy

- a higher incidence of HIV/VL co-infection has been reported in patients with AIDS, manifesting as opportunistic infection

- patients with AIDS and leishmaniasis have a sharp decline in mean survival as compared to non-leishmania infected patients

- WHO recomends sodium stibogluconate (20 $\mathrm{mg} / \mathrm{kg} /$ day for 28 days) as first-line therapy in HIV/VL co-infection, but such patients are often resistant to first-line therapy

- pentamidine, amphotericin $B$, and combined stibogluconate and allopurinol are second-line therapies

- amphotericin B lipid complexes (AmBisome) have been found to be more effective and less toxic in immunocompromised VL patients

- pentavalent antimony given once a month is effective in prevention of relapses

seropositivity of HIV in India is restricted to the urban areas while VL has a predominantly rural and suburban distribution. A study from Bihar, the state with the highest incidence of VL, did not report a single HIV-positive sample from 4567 sera samples obtained from highrisk individuals, showing the low prevalence of HIV infection in rural and semi-urban societies. ${ }^{5}$ Secondly, in a developing country like India, other virulent infections are present in the environment (eg, tuberculosis, bacterial pneumonias, etc) and patients suffering from HIV infection usually die from such infections before they are immunocompromised enough to succumb to opportunistic infections like VL.

However, all this may change in the near future, with rapid liberalisation and economic growth, there has been a greater intermixing of populations from urban and rural areas, and due to better medical care and awareness, patients with HIV/AIDS are surviving longer. Thus India is on the verge of breaking through into the circle of developed countries and it will be facing unique health problems common both to underdeveloped and developed countries in the coming decades.

There is a sharp reduction in mean survival (13 months) in patients with Leishmania/HIV co-infection compared to other AIDS patients. There are also reports of frequent severe VL caused by Leishmania strains with lower or no virulence in HIV-negative individuals, and it has been suggested that LV should be included among the AIDS-defining diseases. ${ }^{12}$ The WHO has recommended treatment with 
sodium stibogluconate $(20 \mathrm{mg} / \mathrm{kg} /$ day for 28 days) as first-line therapy. Pentamidine at a dose of $4 \mathrm{mg} / \mathrm{kg}$ on alternate days for 3-4 weeks, sodium stibogluconate and allopurinol (10 $\mathrm{mg} / \mathrm{kg} /$ day), and amphotericin B (0.5 $\mathrm{mg} / \mathrm{kg} /$ day for 14-21 days) have been used as second-line drugs in HIV/VL co-infected patients, ${ }^{6}$ but have been associated with

1 Desjeux P, Alvar J, Gradoni L, et al. Epidemiological analysis of 692 retrospective cases of Leishmania-HIV coinfection. World Health Organization: Division of Control of Tropical Diseases. WHO Leishmania 1996;39:1-11.

2 Thakur CP. HIV and Leishmania coinfection. F Assoc Physicians India 1997;45:500.

3 Dey AB, Chakravarty S, Nagarkar KM, Khilnani GC, Kumar V. Visceral Leishmaniasis in a patient with AIDS. $\mathcal{f}$ Kumar V. Visceral Leishmaniasis in a patient with AIDS. $\mathcal{F}$ Assoc Physicians India 1997;45:63-4

Vishwas LA, Singh S, Wali JP. Visceral Leishmaniasis in AIDS. F Assoc Physicians India 1997;45:582. relapse, unresponsiveness and low efficacy. More recently, amphotericin B lipid complexes (AmBisome) have been found to be more effective and less toxic in immunocompromised VL patients. ${ }^{6}$ Pentavalent antimony given once a month was effective in prevention of relapse in HIV-infected leishmania patients after initial cure. ${ }^{7}$

\footnotetext{
5 Gupta AK, Saran R. Detection of antibodies to HIV infection among high risk groups in Bihar. Indian 7 Public Health 1993;37:54-6.

6 Gradoni L, Brycesson A, Desjeux P. Treatment of Mediterranean visceral leishmaniasis. Bull World Health Org 1995;73:191-7.

7 Ribera E, Ocana I, Otera J, et al. Prophylaxis of visceral leishmaniasis in Human Immunodeficiency Virus infected patients. Am f Med 1996:100:496-501.
}

\title{
Fatal phenytoin hypersensitivity syndrome
}

\author{
U Mahadeva, M Al-Mrayat, K Steer, E Leen
}

\section{Summary \\ The phenytoin (hydantoin) hypersensitiv- ity syndrome is rare but potentially fatal. Often, as in this case, it presents with non-specific symptoms and signs, requir- ing a high degree of clinical suspicion for diagnosis.}

Keywords: phenytoin; hydantoin; hypersensitivity.

Phenytoin (diphenylhydantoin) is an aromatic ring compound which is metabolised in the liver by hydroxylation of one of its phenyl groups and then excreted in the urine and bile as a glucuronide conjugate. It was first introduced as an anticonvulsant in 1938. Dose-dependent side-effects (neurological impairment, gingival hyperplasia and megaloblastic anaemia) soon became apparent but an idiosyncratic hypersensitivity syndrome to phenytoin (and other hydantoins) was first described in $1959 .{ }^{1}$

We report a case of unrecognised, fatal,

Northwick Park and St Mark's Hospitals NHS Trust, Watford Road, Harrow HA1 3UJ, UK Department of Cellular Pathology U Mahadeva

E Leen

Department of

General Medicine and

Endocrinology

M Al-Mrayat

K Steer

Correspondence to

Dr E Leen, Histopathology

Laboratory, James Connolly

Memorial Hospital,

Blanchardstown, Dublin 15, Ireland

Accepted 7 June 1999 phenytoin hypersensitivity syndrome with characteristic pathological changes in the heart, liver, skin and lymph nodes at autopsy.

\section{Case report}

The patient was an 85-year-old AfroCaribbean woman who was admitted following collapse at home, with drowsiness, fever, rigors and a pruritic rash. Her medical history included a hysterectomy, ischaemic heart disease, type II diabetes mellitus and paraphrenia. One month prior to admission she was diagnosed as having complex partial seizures and was commenced on phenytoin $300 \mathrm{mg}$ at night. Her other medications included metformin $500 \mathrm{mg}$ bid, tolbutamide $500 \mathrm{mg}$ bid, nifedipine $10 \mathrm{mg}$ bid and risperidone $1 \mathrm{mg}$ od. She was a nonsmoker and had stopped taking alcohol since the onset of the fits.

On examination she was unwell and confused with a temperature of $38^{\circ} \mathrm{C}$, regular pulse rate of 90 beats/min and a blood pressure of $120 / 70 \mathrm{mmHg}$. She had a generalised maculopapular erythaematous rash, marked neck stiffness but no photophobia or focal neurological signs. She had a systolic murmur at the apex. Her chest auscultation was normal. Abdominal examination was unremarkable.

The initial working differential diagnoses were septicaemia, a drug reaction, or possible food allergy (the patient was allergic to salmon and she had consumed some one day prior to admission).

The results of initial investigations are presented in box 1 , the most notable abnormal findings were a raised blood eosinophil count and C-reactive protein; a markedly elevated creatine kinase; and grossly deranged liver function tests. Skin biopsy was not performed.

She was treated empirically with intravenous 


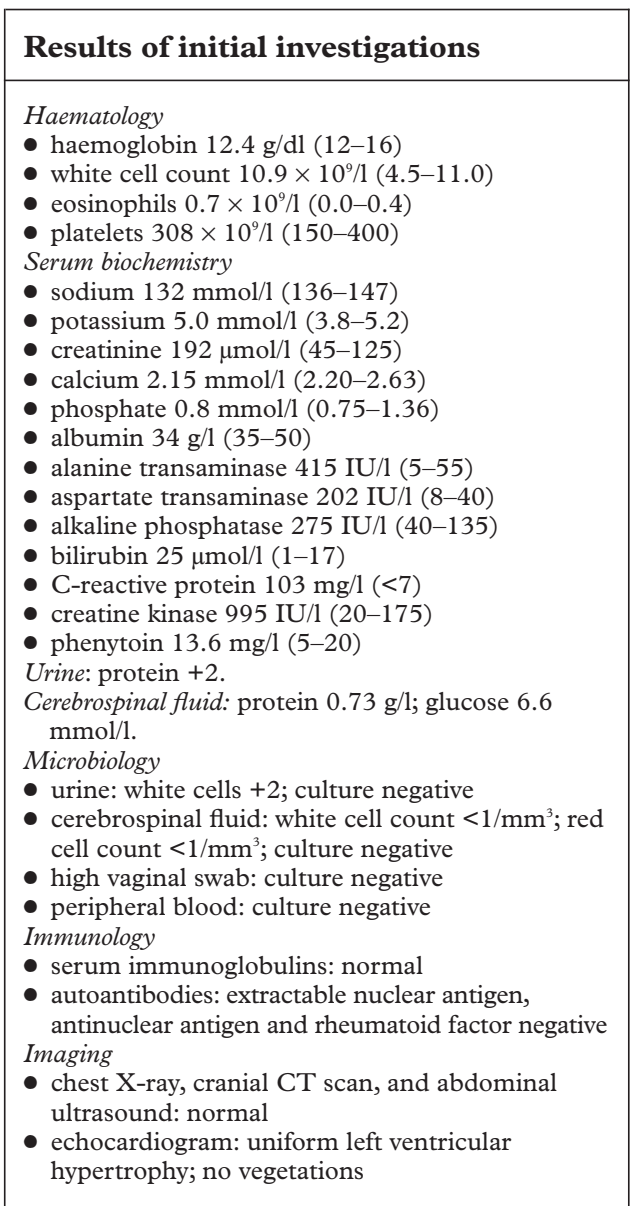

Box 1

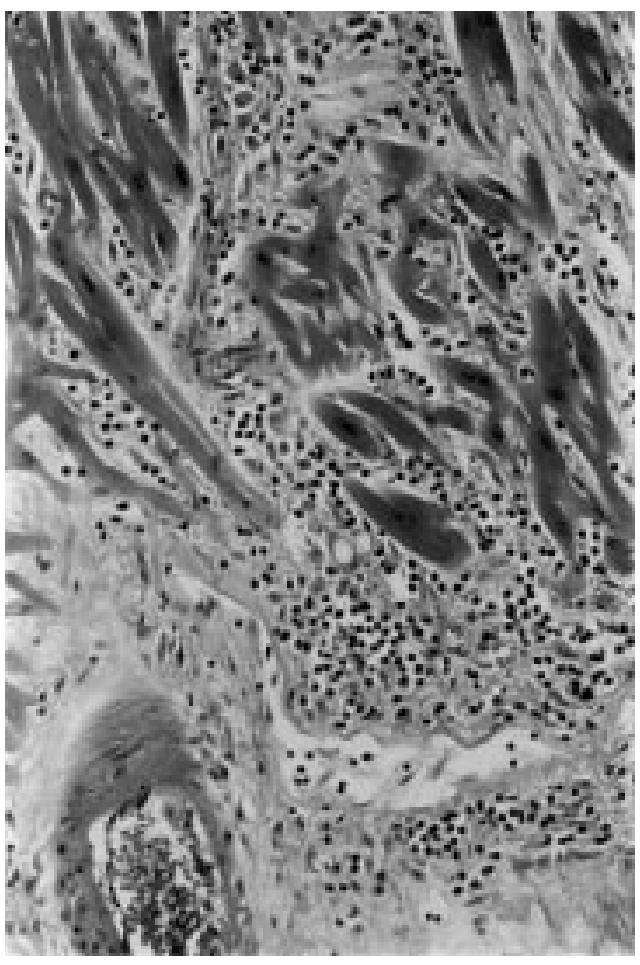

Figure The heart showed myocytolysis and an eosinophil-rich inflammatory infiltrate (Haematoxylin $\&$ eosin, orig $\times 160$ )

\section{Learning points}

- phenytoin hypersensitivity syndrome is rare but potentially fatal. Management is by immediate drug withdrawal and, since the condition is often progressive, many authorities advocate the administration of corticosteroids

- although the characteristic features are fever, rash and lymphadenopathy, presentation is often with non-specific symptoms and signs, and hence diagnosis requires meticulous drug history documentation coupled with a high degree of clinical suspicion

- patients displaying the syndrome and their first degree relatives should be counselled to avoid phenytoin and related anticonvulsants

Box 2

to $3 \mathrm{~cm}$ in diameter). The heart $(270 \mathrm{~g})$ appeared normal. The brain $(1000 \mathrm{~g})$ was small and firm and showed yellowish discolouration of the cortex suggestive of amyloidosis.

Histological examination of the heart showed an interstitial eosinophil-rich infiltrate with myocytolysis. There was no necrosis, vasculitis or fibrosis (figure). These features are characteristic of hypersensitivity myocarditis. ${ }^{2}$ The liver displayed a marked periportal acute and chronic inflammatory infiltrate including increased numbers of eosinophils, with lobular hepatocyte necrosis, consistent with a severe drug-induced hepatitis. The lymph nodes sampled showed loss of the normal follicular architecture with expansion of the paracortical areas. Immunoblasts were not increased in number and these features are consistent with phenytoin-induced pseudolymphoma. ${ }^{3}$ Biopsy of the skin showed a picture of toxic epidermal necrolysis (full thickness epidermal necrosis, separation at the dermo-epidermal junction and a sparse superficial dermal inflammatory infiltrate), also consistent with the phenytoin hypersensitivity syndrome. The sections of lung revealed pulmonary oedema only, with no evidence of infection. The brain displayed classical features of Alzheimer's disease with amyloid angiopathy, extracellular amyloid plaques, neurofibrillary tangles and Hirano bodies.

\section{Discussion}

Phenytoin hypersensitivity syndrome is more common in blacks ${ }^{4}$ and typically has its onset 3 weeks to 3 months after initiation of therapy. Although variable in presentation, its hallmark clinical features are fever, a rash (erythroderma, progressing via a generalised maculopapular to a pustular rash and finally desquamation), lymphadenopathy and hepatosplenomegaly. ${ }^{3-6}$ Peripheral leucocytosis and eosinophilia are common. Potentially fatal complications associated with the syndrome include hypersensitivity myocarditis, ${ }^{2}$ druginduced hepatitis with or without hepatocyte necrosis (which carries a mortality of up to $50 \%),{ }^{2}$ and compromise of renal and pulmonary functions.

As with any drug hypersensitivity reaction, prompt cessation of phenytoin is the first 
essential step in management. ${ }^{8} \mathrm{~A}$ benzodiazepine should be substituted for seizure control, ${ }^{9}$ as was done with our patient. However, despite termination of phenytoin, the hypersensitivity reaction is often progressive and it is hence common practise to administer corticosteroids. $^{8}$ The role of systemic corticosteroids in phenytoin hypersensitivity has not been studied in a randomised, placebocontrolled trial and its use is based only on anecdotal evidence. ${ }^{89}$

The underlying mechanisms of the phenytoin hypersensitivity syndrome are unknown'; immune complex, ${ }^{10}$ and delayed-type hyper-

1 Saltzstein SL, Ackerman LV. Lymphadenopathy induced by nticonvulsant drugs and mimicking clinically and pathoogically malignant lymphomas. Cancer 1959;12:164-82.

2 Taliercio CP, Olney BA, Lie JT. Myocarditis related to drug hypersensitivity. Mayo Clin Proc. 1985;60:463-8.

3 Abbondanzo SL, Irey NS, Frizzera G. Dilantin-associated lymphadenopathy. Am $\mathcal{F}$ Surg Pathol 1995;19:675-86.

4 Potter T, DiGregorio F, Stiff M, Hashimoto K. Dilantin hypersensitivity syndrome imitating Staphylococcal toxic shock. Arch Dermatol 1994;130:856-8.

5 Kleier RS, Breneman DL, Boiko S.Generalized pustulation as a manifestation of the anticonvulsant hypersensitivity syndrome. Arch Dermatol 1991;127:1361-4.

6 Holland P, Mauer AM. Diphenylhydantoin-induced hypersensitivity reaction. $\mathcal{F}$ Pediatr 1965;66:322-32. sensitivity allergic reactions, ${ }^{7}$ alteration of lymphocyte function and toxic metabolite production $^{48}$ have been postulated. Genetic factors are also thought to contribute, since siblings are said to have a one in four risk of showing a similar reaction. ${ }^{589}$ Cross-reactivity with other aromatic ring anticonvulsants (eg, phenobarbital and carbamazepine) has been reported in patients with a history of phenytoin hypersensitivity. ${ }^{4} 589$

We wish to acknowledge the assistance of Dr S Al-Sarraj, Consultant Neuropathologist, Institute of Psychiatry, London.

7 Mullick FG, Ishak KG. Hepatic injury associated with diphenylhydantoin therapy. Am f Clin Pathol 1980;74:442-52.

8 Handfield-Jones SE, Jenkins RE, Whittaker SJ, Besse CP, McGibbon DH. The anticonvulsant hypersensitivity syndrome. Br F Dermatol 1993;129:175-7.

9 Carmela C, Vittorio MD, Jennie J, Muglia MD. Anticonvulsant hypersensitivity syndrome. Arch Intern Med 1995;155: 2285-90.

10 Zidar BL, Mendelow H, Winkelstein A, Shadduck RK. Diphenylhydantoin-induced serum sickness with fibrinplatelet thrombi in lymph node microvasculature. Am f Med 1975;58:704-7. 


\title{
Management of pulmonary thrombo-embolism using catheter manipulation: a report of four cases and review of the literature
}

\author{
Peter S C Wong, Shyam P Singh, Robert D S Watson, Gregory Y H Lip
}

\begin{abstract}
Summary
To date the management of pulmonary thrombo-embolism is still largely limited to anticoagulation. Heparin and oral anticoagulation have been shown to be effective in reducing recurrence and death in venous thrombo-embolism. During the acute stage, systemic thrombolytic therapy has also been advocated for the rapid dissolution of the thrombus in patients with haemodynamic instability. We describe four patients with acute pulmonary thrombo-embolism who were managed with catheter-based thrombus manipulation with intrapulmonary thrombolysis. This management strategy should be considered in patients with pulmonary thrombo-embolism who continue to deteriorate despite conventional management with anticoagulation or systemic thrombolysis.
\end{abstract}

Keywords: pulmonary thrombo-embolism; catheter manipulation; thrombus; thrombolytic therapy

Pulmonary thrombo-embolism (PE) is a common cause and consequence of hospital admission, with a significant mortality and morbidity. Male sex, old age, serious medical or surgical diseases, immobilisation and trauma are important predisposing factors in patients dying of such disease. ${ }^{1}$ Untreated PE is associated with a mortality rate of approximately $30 \%$, but can be decreased to $1-10 \%$ with the institution of appropriate diagnosis and treatment..$^{2-5}$

PE usually results from acute obstruction by thrombus, at any location of the pulmonary vascular tree. If severe, it leads to haemodynamic deterioration, systemic acidosis, right heart failure, cardiogenic shock, and ultimately death. To date, the management of PE is still largely limited to anticoagulation. Unfractionated heparin, nicoumalone and warfarin have been shown to be effective in reducing recurrence and death in venous thromboembolism, ${ }^{45}$ and more recently, low-molecularweight heparins are increasingly used with their relative ease of administration and lack of requirement for anticoagulation monitoring. ${ }^{6}$ During the acute stage, systemic thrombolytic therapy has been advocated for the rapid dissolution of the thrombus, with some acute reduction of pulmonary artery pressure; nevertheless more evidence is needed for its long-term prog- nostic benefit, although it may have a role in patients with haemodynamic instability, as such patients have a mortality rate of approximately $20 \%$, despite the use of anticoagulants and other supportive measures. ${ }^{78}$

Besides systemic thrombolytic therapy, there have been isolated reports on the use of pulmonary angiography and catheter-based manipulation with intrapulmonary thrombolysis to achieve clot fragmentation and dissolution (table 1) ${ }^{9-13}$ We describe four patients who presented to our centre with massive PE who were managed with catheter manipulation and intrapulmonary thrombolysis.

\section{Case reports}

\section{Case 1}

A 46-year-old Caucasian man was admitted after an assault resulting in a closed fracture of the neck of left humerus and left wrist. He had a medical history of mild asthma and was a non-smoker. Both arm fractures were reduced under general anaesthesia and a piece of autologous bone graft was used to seal the humoral fracture with a metal plate. He was mobilised and well for 3 days postoperatively, when he suddenly experienced acute onset dyspnoea, and became tachycardic (130 beats/ min in sinus rhythm) and hypotensive $(86 / 58$ $\mathrm{mmHg})$. His white cell count was $21.6 \times 10^{9} / 1$ and arterial blood gases showed $\mathrm{pH} 7.34, \mathrm{pCO}_{2}$ $3.7 \mathrm{kPa}, \mathrm{pO}_{2} 9.9 \mathrm{kPa}$, bicarbonate $17.5 \mathrm{mmol} / \mathrm{l}$ and base excess of -8.6 . Central venous pressure was elevated at $+29 \mathrm{~cm}$ water. A bedside transthoracic echocardiogram showed a dilated right atrium and ventricle with impaired right ventricular contraction. Left ventricular contraction was normal.

A clinical diagnosis of $\mathrm{PE}$, originating from an axillary vein thrombosis, was made and 95\% oxygen was adminstered through a rebreathing mask with subsequent arterial gases showing $\mathrm{pH}$ 7.36, $\mathrm{pCO}_{2} 4.1 \mathrm{kPa}, \mathrm{pO}_{2} 11.2 \mathrm{kPa}$, bicarbonate $19.7 \mathrm{mmol} / \mathrm{l}$ and base excess -5.8 . A bolus of 5000 units intravenous (iv) unfractionated heparin was given, followed by an infusion rate of 25000 units over the next 24 hours. Colloid (haemacel) and dopamine at $2-5 \mu \mathrm{g} / \mathrm{kg} / \mathrm{min}$ were given iv to optimise systemic and renal output. However, the condition of the patient continued to deteriorate, with persistent hypotension and increasing hypoxia, and heparin was substituted for a systemic infusion of iv streptokinase at 100000 
Table 1 Right heart catheterisation, pulmonary angiography and catheter manipulation for pulmonary embolus examples of studies in the literature

\begin{tabular}{|c|c|c|c|c|c|}
\hline Authors & Greenfield et $a l^{9}$ & Fava et al ${ }^{10}$ & Stock et al ${ }^{11}$ & Brady et al ${ }^{12}$ & Essop et $a l^{13}$ \\
\hline No of patients & 46 & 16 & 5 & 3 & 5 \\
\hline Mean age (years), (range) & $54(17-83)$ & $49(20-68)$ & $50(21-80)$ & $30(18-71)$ & $35(21-47)$ \\
\hline Male:female & $25: 21$ & $8: 8$ & $3: 2$ & $0: 3$ & $1: 4$ \\
\hline Severity of PE & $\begin{array}{l}42 \text { hypotension } \\
4 \text { mechanical ventilation }\end{array}$ & $\begin{array}{l}\text { massive } \\
\geqslant 2 \text { lobar arteries }\end{array}$ & massive & $\begin{array}{l}2 \text { shock } \\
1 \text { arrest }\end{array}$ & shock \\
\hline $\begin{array}{l}\text { Onset of symptoms to } \\
\text { procedure }\end{array}$ & - & $<5$ days & $\leqslant 10$ hours & - & $<5$ days \\
\hline Catheters and guidewire & $\begin{array}{l}12 \mathrm{~F} \text { stainless steel double } \\
\text { lumen with suction cup }\end{array}$ & $\begin{array}{l}6 \text { F pigtail; } \\
\text { Grollman angioplasty } \\
\text { balloon length } \\
(12-16 \mathrm{~mm})\end{array}$ & $\begin{array}{l}6-7 \mathrm{~F} \text { pigtail; } \\
0.035 \text { " Terumo; } \\
\text { angioplasty balloon length } \\
(8-10 \mathrm{~mm})\end{array}$ & $\begin{array}{l}\text { Goodale-Lubin pigtail; } \\
\text { J guide wire }\end{array}$ & $\begin{array}{l}\text { diagnostic pigtail; } \\
\text { Berman manipulation } \\
\text { multipurpose end-hole; } \\
035 \text { guide wire }\end{array}$ \\
\hline Catheter procedure & embolectomy & fragmentation & fragmentation & fragmentation & fragmentation \\
\hline Thrombolysis via catheter & - & in 8 patients & yes & in 2 patients & yes \\
\hline Heparin & - & yes & - & yes & - \\
\hline Index of improvement & - & $\begin{array}{l}\text { mean PAP reduced } \\
\text { from } 48 \text { to } 19 \mathrm{mmHg}\end{array}$ & $\begin{array}{l}\text { mean PAP reduced from } \\
49 \text { to } 28 \mathrm{mmHg}\end{array}$ & - & - \\
\hline Outcome & $\begin{array}{l}14 \text { died at } 30 \text { days; } \\
32 \text { survivors; } \\
1 \text { surgical embolectomy }\end{array}$ & $\begin{array}{l}1 \text { died } \\
15 \text { survivors }\end{array}$ & all survivors & all survivors & $\begin{array}{l}1 \text { died } 2 \text { weeks after } \\
\text { discharge }\end{array}$ \\
\hline Complications & $\begin{array}{l}\text { haematoma } 15 \% \text {; } \\
\text { pulmonary infarct } 11 \% \text {; } \\
\text { myocardial infarct } 4 \% \text {; } \\
\text { ruptured pulmonary artery } \\
2 \% \text {; ventricular perforation } \\
2 \%\end{array}$ & haematoma $19 \%$ & $\begin{array}{l}\text { retroperitoneal and groin } \\
\text { haematoma } 40 \% \text {; } \\
\text { minor haematoma } 40 \%\end{array}$ & minor bleeding $67 \%$ & - \\
\hline
\end{tabular}

units/h. He was referred to the on-call cardiologists for pulmonary angiography and clot manipulation.

Via a right femoral venous puncture, a $6 \mathrm{~F}$ Gensini catheter (Cordis) was manipulated into the heart. The mean right atrium (RA) pressure was $18 \mathrm{mmHg}$, right ventricle (RV) pressure $50 / 5 \mathrm{mmHg}$ (mean 26) and pulmonary artery (PA) pressure $55 / 20 \mathrm{mmHg}$ (mean 32). Pulmonary angiography confirmed a large thrombus obstructing the left main pulmonary artery. The Gensini catheter and a J guide wire (0.038", USCI) were used under direct image intensifier control for attempted clot fragmentation, resulting in the clot successfully being dispersed to a more peripheral location. The catheter was then left in situ, in close proximity to the residual thrombus for further streptokinase infusion. A repeat right heart catheter the following day revealed a mean RA pressure of 15 $\mathrm{mmHg}$ and PA pressure of 42/16 $\mathrm{mmHg}$ (mean

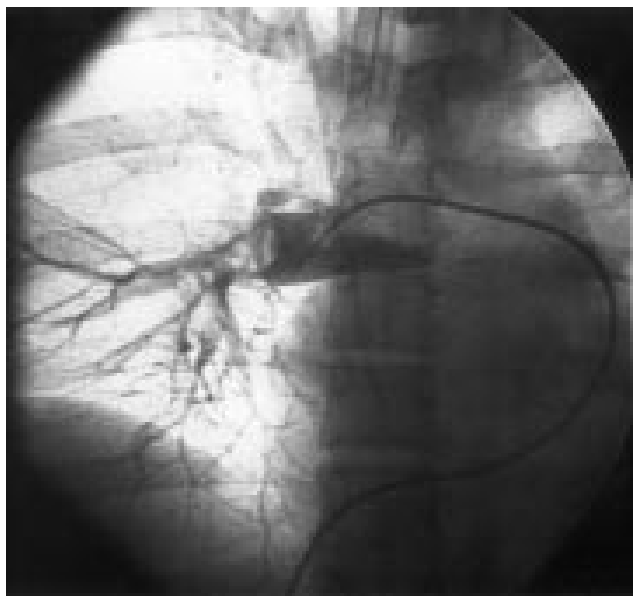

Figure 1 Pulmonary angiograms demonstrating thrombus within the right pulmonary artery (case 2)
26) with some persistence of the clot, although smaller in size. A further attempt at clot fragmentation and clot dispersion was made with a $8 \mathrm{~F}$ pigtail catheter (Cordis) with the clot displaced to an even more peripheral location.

The post-procedure course was complicated by acute renal failure which was treated with haemofiltration for 7 days. The patient recovered fully and was discharged home on Day 30.

\section{Case 2}

A 18-year-old woman was transferred to our unit from a local orthopaedic hospital after developing a persistent sinus tachycardia, hypotension and poor arterial oxygen saturation in the immediate postoperative period. She had undergone an endoprosthetic replacement of the left tibia after excision of an osteosarcoma. She had been treated with subcutaneous heparin. On arrival in our hospital, 22 hours after her initial deterioration, her temperature

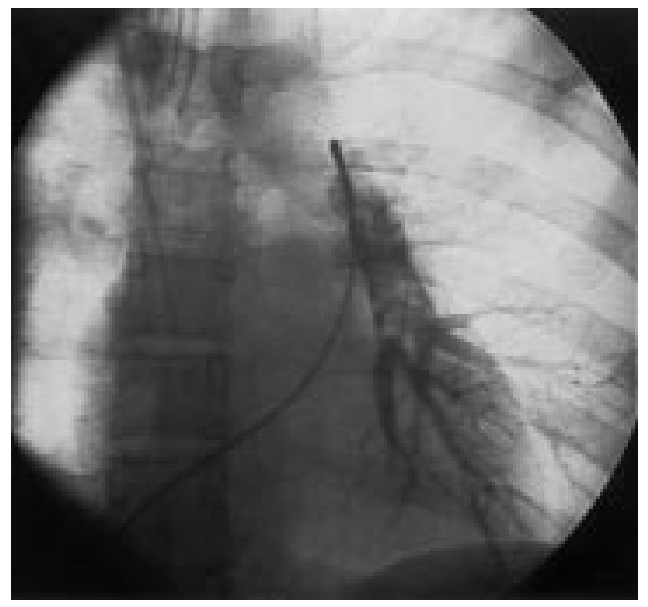

Figure 2 Pulmonary angiograms demonstrating thrombus within the left pumonary artery (case 2) 
Table 2 Summary of the four case histories

\begin{tabular}{|c|c|c|c|c|}
\hline & Case 1 & Case 2 & Case 3 & Case 4 \\
\hline Age & 46 & 18 & 30 & 36 \\
\hline Sex & male & female & female & male \\
\hline Predisposing factors & fracture; axillary vein thrombosis & osteosarcoma & hospitalisation & pneumonia nephrotic syndrome \\
\hline Severity of pulmonary artery obstruction & left main & $\begin{array}{l}\text { all major intermediate } \\
\text { branches }\end{array}$ & $\begin{array}{l}\text { right upper and middle } \\
\text { intermediate branches }\end{array}$ & right main \\
\hline \multirow[t]{2}{*}{ Catheters } & 6 F Gensini & 6 F Gensini & $8 \mathrm{~F}$ pigtail & 6 F Gensini \\
\hline & $\begin{array}{l}8 \mathrm{~F} \text { pigtail } \\
\mathrm{J} \text { guide wire }\end{array}$ & $\mathrm{J}$ guide wire & $\mathrm{J}$ guide wire & $\mathrm{J}$ guide wire \\
\hline Catheter manipulation & yes & limited & yes & yes \\
\hline Index of improvement & $\begin{array}{l}\text { mean } \mathrm{PAP} \text { reduced from } 32 \text { to } \\
26 \mathrm{mmHg}\end{array}$ & - & $\begin{array}{l}\text { mean PAP reduced from } \\
28 \text { to } 12 \mathrm{mmHg}\end{array}$ & - \\
\hline Thrombolysis & yes & yes & yes & yes \\
\hline Outcome & alive & dead & alive & alive \\
\hline
\end{tabular}

was $38^{\circ} \mathrm{C}$, pulse 150 beats $/ \mathrm{min}$, blood pressure $85 / 60 \mathrm{mmHg}$, and central venous pressure +16 $\mathrm{cm}$ water. Mechanical ventilation was in situ and arterial blood gases showed a $\mathrm{pH} 7.2, \mathrm{pCO}_{2} 6.8$ $\mathrm{kPa}, \mathrm{pO}_{2} 20 \mathrm{kPa}$, bicarbonate $18.4 \mathrm{mmol} / \mathrm{l}$ and base excess of -7.6. An electrocardiogram (ECG) confirmed sinus tachycardia, with a frontal axis +800 , right bundle branch block and a S1Q3T3 pattern.

As a result of her critical condition, right heart catheterisation and pulmonary angiography was performed immediately upon arrival (figures 1 and 2). Mean RA pressure was $14 \mathrm{mmHg}$, RV 50/0 mmHg (mean 25), and PA $42 / 20 \mathrm{mmHg}$ (mean 32). Bilateral thrombi were visualised to obstruct all intermediate pulmonary branches during pulmonary angiography. An attempt to disperse some of the clots to a peripheral location was made, and the cardiac catheter was left in situ for a continuous streptokinase infusion at 100000 units/h. The patient was transferred to the Intensive Care Unit for continued ventilation, but remained in cardiogenic shock, with a blood pressure of $40 / 20 \mathrm{mmHg}$, despite ionotropic support (iv adrenaline boluses in addition to background infusion of $800 \mu \mathrm{g} / \mathrm{kg} / \mathrm{min}$ ) and died later that day with no reponse to therapeutic measures.

Case 3

A 30-year-old woman was admitted with a history of dyspnoea and collapse following a recent in-patient stay for a minor superficial leg injury. She was a smoker and was previously in good health. On examination she had a tachycardia of 138 beats $/ \mathrm{min}$, with a blood pressure 90/50 mmHg. The ECG showed sinus tachycardia with widespread ST segment depression. A chest X-ray was unremarkable. PE was suspected on clinical grounds and confirmed with a pulmonary angiogram, which demonstrated the presence of blocked pulmonary arterial branches in the right upper and middle intermediate branches. The mean RA pressure was $12 \mathrm{mmHg}$, and PA pressure was $45 / 16$ mmHg (mean 28). A $8 \mathrm{~F}$ pigtail catheter (Cordis) was used to disperse the thrombi and the catheter left in the right main pulmonary artery for continuous streptokinase infusion. A repeat pulmonary angiogram performed 2 days later showed complete dissolution of thrombus and patient was discharged on warfarin after 8 days of hospitalisation.
Case 4

A 36-year-old male smoker presented with leftsided pleuritic chest pain, dyspnoea and a productive cough. An initial diagnosis of left lower lobe pneumonia was made and treatment with antibiotics initiated. On day 2 , he experienced a sudden onset of increasing dyspnoea. arterial blood gases revealed severe hypoxaemia with $\mathrm{pH} 7.4, \mathrm{pCO}_{2} 3.9 \mathrm{kPa}, \mathrm{pO}_{2} 5.3 \mathrm{kPa}$, bicarbonate 22.6 and a base excess of -1.6 . Chest X-ray confirmed pneumonic consolidation in the left lower zone whilst the rest of the lung fields was clear. An ECG showed sinus tachycardia without evidence of myocardial ischaemia.

In view of the mismatch between the degree of hypoxaemia and consolidation, and deteriorating clinical state (increasing dyspnoea, hypotension and hypoxia), a PE was suspected. Pulmonary angiography using a size 6 Gensini catheter (Cordis) revealed a major obstruction of the right main pulmonary artery with thrombus, and clot dispersion was attempted using the catheter and J guide wire (0.038", USCI). Streptokinase was then infused via the catheter into the pulmonary artery. A repeat pulmonary angiogram 2 days later showed satisfactory perfusion to all areas of the right lung. The patient was subsequently discharged on Day 15. Subsequent clinic follow-up investigations revealed the presence of nephrotic syndrome secondary to membraneous glomerulonephritis.

\section{Discussion}

The diagnosis of $\mathrm{PE}$ is often made too late, at the patient's peril. When the thrombotic occlusion causes major haemodynamic compromise, as in our four cases, the diagnosis is seldom in doubt. The diagnosis is, however, less obvious in less severe cases, as symptoms are vague, non-specific or may even be absent initially. Simple investigations such as chest radiography and ECG are often inadequate. ${ }^{14}{ }^{15}$ Bedside transthoracic echocardiography can provide some information to substantiate the diagnosis, as right ventricular dilatation with hypokinesis, abnormal septal position and paradoxical systolic motion, reduced left ventricular size, pulmonary artery dilatation, tricuspid and pulmonary regurgitation, and a lack of collapse of the inferior vena cava with inspiration are features suggestive of PE on the echocardiogram. ${ }^{16}$ The visualisation of 
thrombus in the right side of the heart or pulmonary artery is less common, but confirms the diagnosis. ${ }^{16}{ }^{17}$ More sophisticated investigations such as lung ventilation-perfusion scans, transoesophageal echocardiography and spiral computed tomography can add to the diagnostic accuracy in patients who are clinically stable enough to undergo these tests, which may add to the delay in making the diagnosis in more urgent situations.

Unfractionated heparin is no doubt the initial treatment of choice in the milder form of PE without haemodynamic instability or significant hypoxaemia. However, this form of treatment is associated with some uncertainity about the level of anticoagulation during the initial but crucial phase of PE. Systemic thrombolytic treatment has been advocated in some patients with PE associated with circulatory instability or hypoxaemia although larger studies with more outcome data are still needed. Although previous studies have demonstrated the short-term superiority of thrombolysis in terms of resolution of both radiographic and haemodynamic abnormalities when measurements were made within the first 24 hours, this does not appear to be sustained nor translated into a mortality benefit. ${ }^{78}$

In selected patients where anticoagulation or thrombolytic therapy are contraindicated, or fulminant PE is evident, pulmonary angiography and catheter-based manipulation can be life saving, although more evidence from randomised controlled trials is needed. Pulmonary angiography provides the gold standard for initially visualising the presence of thromboemboli in the pulmonary vasculature. Our usual practice is to perform this under local anaesthetic from the femoral vein, using a Seldinger technique; visualisation is performed in the postero-anterior position with injection of $35 \mathrm{ml}$ of dye (Niopam 340) at $14 \mathrm{ml} / \mathrm{s}$ and a pressure of 900 psi via a pigtail or Gensini catheter. The risks of undertaking pulmonary angiography relate to bleeding at the groin (especially with concomitant anticoagulants), possible reactions to the contrast (allergy, renal impairment) and rarely, perforation of the right ventricle.

As illustrated with our cases, intravascular catheters or balloon angioplasty can be used to dislodge or fragment thrombus in a proximal segment of the pulmonary artery, to be dispersed to a more peripheral location. Such manoeuvres can lower the pulmonary vascular resistance, reduce strain on the right side of the heart, and improve perfusion to the affected lung segments. Concomitant use of thrombolytic therapy either via pulmonary artery catheter or peripheral venous catheter can be synergistic with catheter-based manipulation for the treatment of $\mathrm{PE}$, in the absence of contraindications. Our usual prac-

1 Anderson FA, Jr, Brownell Wheeler H, Goldberg RJ, et al. A population-based perspective of the hospital incidence and case-fatality rates of deep vein thrombosis and pulmonary embolism. A Worcester DVT study. Arch Intern Med 1991;151:933-8.

2 Kanis JA. Heparin in the treatment of pulmonary thromboembolism. Thromb Haemost 1974;;32:517. tice is to administer streptokinase, initially 250 000 units over 30 minutes, followed by 100 000 units/h for $24-72$ hours. The introduction of newer agents such as the glycoprotein IIb/IIIa receptor antagonists may provide alternative antithrombotic strategies in the future, but further trials are needed to confirm the value of these agents.

A large number of different catheters have been used in clinical reports (table 1) since Greenfield ${ }^{18}$ originally described the technique of transvenous catheter pulmonary embolectomy. The pigtail catheter is familiar to all cardiologists and because of its round coil design, could be regarded as one of the least trauma-inducing catheter. Moreover, the pigtail coil design can be utilised to a greater advantage by maximising the surface area with the 'loop upon axial rotation' ability of the catheter, which facilitates the dislodgement and fragmentation of the thrombus. This approach with the pigtail catheter was been used satisfactorily in two of our cases. In addition to the catheter shape, a larger size catheter with a bigger pigtail loop may be easier and more effective to manoeuvre than a smaller catheter of the same design; perhaps more purpose built catheters may be available in the future for this procedure.

At present, there are no data to support the routine use of pulmonary angiography and catheter-based manipulation in all cases of PE. This therapeutic measure should perhaps be reserved for cases whereby there are contraindications to anticoagulation or thrombolysis, or in patients with a rapidly deteriorating clinical course. Surgical embolectomy with or without inferior vena cava filter is another alternative to catheter-based manipulation in severe cases or in the presence of contraindications to thrombolysis, but its place in the management of PE remains controversial. ${ }^{19}{ }^{20}$ Indeed, the operative mortality of surgical embolectomy in selected patients has been reported to be high, up to $40-70 \%,{ }^{19}{ }^{20}$ and the availability of an emergency cardiothoracic team would limit its widespread application.

In conclusion, we present four cases of acute PE where catheter-based thrombus manipulation with intrapulmonary thrombolysis were used, with a satisfactory outcome in three patients. We do accept that our patients had multiple interventions, including intravenous heparin, and intravenous and intrapulmonary thrombolysis, but we suggest that catheterbased thrombus manipulation with intrapulmonary thrombolysis could be considered in patients with PE who continue to deteriorate despite conventional management with anticoagulation or systemic thrombolysis, especially in centres with access to angiographic facilities.

3 Carlson JL, Kelley MA, Duff A, et al. The clinical course of pulmonary embolism. N Engl f Med 1992;326:1240

4 Pollak EW, Sparks FC, Barker WF. Pulmonary embolism: an appraisal of therapy in 516 cases. Arch Surg 1973;107:66-8.

5 Barritt DW, Jordan SC. Anticoagulant drugs in the treatment of pulmonary embolism - a controlled trial. Lancet $1960 ; 1309-12$. 
6 Thery C, Simonneau G, Meyer G, et al. Randomised trial of subcutaneous low-molecular-weight heparin CY 216 (Fraxiparine) compared with intravenous heparin in the

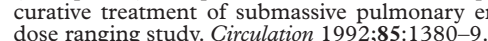

7 Thrombolytic therapy in thrombosis: A National Institutes of Health consensus development conference. Ann Intern Med 1980;93:141.

8 Goldhaber SZ. Contemporary pulmonary embolism thrombolysis. Chest 1995;107(suppl 1):51S.

9 Greenfield LJ, Proctor MC, Williams DM, Wakefield TW. Long term experience with transvenous catheter pulmonary embolectomy. ₹ Vasc Surg 1993;18:450-8.

10 Fava M, Loyola S, Flores P, Huete I. Mechanical fragmentation and pharmacological thrombolysis in massive pulmonary embolism. F Vasc Interv Radiol 1997;8:261-6.

11 Stock KW, Jacob AL, Schnabel KJ, Bongartz G, Steinbrich W. Massive pulmonary embolism: treatment with thrombus fragmentation and local fibrinolysis with recombinan human tissue plasminogen activator. Cardiovasc Interv 2 Radiol 1957,20:364-8.

2 Brady AJB, Crake T, Oakley CM. Percutaneous catheter fragmentation and distal dispersion of proximal pulmonary embolus. Lancet 1991;338:1186-9.
13 Essop MR, Middlemost S, Skoularigis J, Sareli P. Simultaneous mechanical clot fragmentation and pharmacologic thrombolysis in acute massive pulmonary embolism. Am f Cardiol 1992;69:427-30.

14 Hyers TN, Hull RD, Weg JG. Antithrombotic therapy for venous thromboembolic disease. Chest 1995; 108:335S

5 Janata-Schwatczek K, Weiss K, Riezinger I, Bankier A, Domanovits H, Seidler D. Pulmonary embolism II. Diagnosis and treatment. Semin Thromb Hemostas 1996;22:33-52.

16 Come PC. Echocardiographic evaluation of pulmonary embolism and its response to therapeutic interventions. Chest 1992;101(suppl):151-62.

17 Evans BH, Maurer G. Echocardiographic diagnosis of pulmonary embolus. Am Heart f 1990;120:1236-68.

18 Greenfield LJ, Kimmell GO, McCurdy WC. Transvenous removal of pulmonary emboli by vacuum-cup catheter technique. ₹ Surg Res 1969;9:347-8.

19 Oakley CM. There is no place for acute pulmonary embolectomy. Br f Hosp Med 1989;41:469.

20 Luciani N, Gaudino M, Possati G. Surgical treatment of massive pulmonary embolism. Rays 1996;21:432-8. 


\title{
Mesenteric infarction due to combined protein C deficiency and prothrombin 20210 defects
}

\author{
C J Mainwaring, M Makris, W E G Thomas, K K Hampton, F E Preston
}

\begin{abstract}
Summary
The prothrombin gene mutation, 20210A, a guanine to adenine substitution at nucleotide position 20210 , has recently been described as an additional risk factor for venous thromboembolic disease. We describe the case of a patient with combined heterozygous prothrombin 20210A mutation and type 1 protein $C$ deficiency who presented with massive mesenteric venous infarction of his small bowel and survived following the use of protein $\mathrm{C}$ concentrate and extensive small bowel resection.
\end{abstract}

Keywords: mesenteric venous infarction; protein C deficiency; prothrombin 20210A

A 49-year-old man presented with diffuse abdominal pain and no bowel action for 3 days. In 1975 surgery for a perforated duodenal ulcer had been complicated by a postoperative right leg deep venous thrombosis (DVT). Since then he had five further spontaneous DVTs related to erratic anticoagulation control. A thrombophilia screen performed in 1996 confirmed heterozygous type 1 protein C deficiency. Reinvestigation following this admission identified an additional thrombophilic defect, the prothrombin 20210 mutation. His baseline protein $\mathrm{C}$ antigen and activity levels, when not on warfarin, were reduced at 0.39 and $0.35 \mathrm{IU} / \mathrm{ml}$, respectively (normal range $0.71-1.42$ ). Family studies had shown that both his son and daughter were similarly affected though asymptomatic. Neither his parents nor his siblings had been tested for thrombophilic defects. Because of recurrent thrombotic events he had been maintained on long-term warfarin since 1993, but on the day of admission his anticoagulation was subtherapeutic with an international normalised ratio (INR) of 1.3. Clinical examination demonstrated diffuse abdominal tenderness only. Investigations revealed a raised white blood cell count of $11.8 \times 10^{9} / 1$ with a neutrophilia, normal chest and abdominal radiology, biochemical screens and serum amylase. A gastroscopy demonstrated bile reflux and minimal gastric ulceration without bleeding. $\mathrm{He}$ continued to deteriorate despite full supportive care with increasing abdominal distention, absent bowel sounds and guarding. In view of these findings, in the context of a thrombophilic disorder, a small bowel infarction was suspected and a mesenteric angiogram confirmed extensive portal, splenic and
Table The use of protein $\mathrm{C}$ concentrate and protein $\mathrm{C}$ levels achieved in a congenitally deficient patient with mesenteric venous thrombosis

\begin{tabular}{llll}
\hline Day & $\begin{array}{l}\text { Protein C concentrate } \\
\text { dose (units given)* }\end{array}$ & $\begin{array}{l}\text { Pre level } \\
\text { (units/ml) }\end{array}$ & $\begin{array}{l}\text { Post level } \\
\text { (units/ml) }\end{array}$ \\
\hline 0 & 2850 & 0.1 & 0.57 \\
+1 & 2850 & 0.29 & 0.72 \\
+2 & None & 0.67 & - \\
+3 & 2850 & 0.49 & 0.86 \\
+4 & 2850 & 0.44 & 0.79 \\
+5 & None & 0.3 & - \\
+6 & None & 0.21 & - \\
+7 & None & 0.19 & - \\
\hline
\end{tabular}

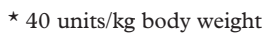

proximal superior plus inferior mesenteric venous thromboses. Pre-operatively he was treated with 2850 units (40 units $/ \mathrm{kg}$ ) of intravenous protein C concentrate (Immuno, Vienna) by bolus injection which increased his levels from 0.1 to $0.57 \mathrm{IU} / \mathrm{ml}$.

At operation, extensive venous infarction of most of the small bowel was noted, requiring resection, together with anastomosis of the remaining viable $4.5 \mathrm{~cm}$ of jejenum and $7.5 \mathrm{~cm}$ of ileum. Postoperatively he was treated with once daily protein $\mathrm{C}$ concentrate, by bolus injection aiming for a protein $\mathrm{C}$ level of greater than $0.50 \mathrm{IU} / \mathrm{ml}$, from day +1 to +4 (table) and intravenous heparin, until the activated partial thromboplastin time ratio was stably maintained at 1.5-2.5. There were no further thromboembolic events. The half-life of the infused protein C concentrate was calculated at $16.2 \mathrm{~h}$ on day +1 and $13.6 \mathrm{~h}$ on day +4 . The longer than anticipated half-life, normally $6 \mathrm{~h}$, probably reflected recovery of endogenous protein $C$ levels whilst not receiving warfarin. Conversion to subcutaneous low molecular weight heparin occurred on day +13 and he was discharged home on day +17 . Warfarin was restarted some 6 weeks postoperatively with erratic anticoagulation control initially as a result of impaired absorption. Currently, he remains well on life-long anticoagulation, with no further thrombotic complications, aiming for a target INR of 2.5. ${ }^{1}$

\section{Discussion}

Mesenteric venous thrombosis (MVT) causing small bowel infarction is an extremely rare cause of an acute surgical abdomen and often difficult to diagnose. Predisposing factors include acquired conditions such as congestive cardiac failure, atrial fibrillation, myeloproliferative disorders, oral contraceptive use and abdominal infections. Our patient had no 


\begin{tabular}{|l|}
\hline $\begin{array}{l}\text { Genetic factors predisposing to venous } \\
\text { thrombosis }\end{array}$ \\
\hline - antithrombin deficiency \\
- protein C deficiency \\
- factor V Leficiency \\
- prothrombin $20210 \mathrm{~A}$ mutation \\
\hline
\end{tabular}

acquired risk factors. MVT has also been described in inherited thrombophilias (box 1), including antithrombin deficiency ${ }^{2}$ and the factor V Leiden mutation. ${ }^{3}$ The prothrombin gene mutation $20210 \mathrm{~A}$ is a recently described additional thrombophilic risk factor with an incidence of $2.3 \%$ in healthy control subjects and $18 \%$ in patients with a personal or family history of DVT. ${ }^{4}$ It is now recognised that some thrombophilic patients can be double heterozygotes for two inherited conditions with an increased relative risk for venous thromboembolic disease. ${ }^{5}$ Our patient had combined heterozygous type 1 protein $\mathrm{C}$ deficiency and the prothrombin 20210A mutation, which probably accounts for the severity of his thromboembolic complications. Additionally, on admission to hospital he had a subtherapeutic INR which would have provided inadequate protection combined with the fact that warfarin further lowers the levels of vitamin-Kdependent protein $\mathrm{C}$, which was intrinsically reduced in this patient. The importance of strict anticoagulation control cannot be overstated and it is possible that this case may have been avoided if his INR had not been allowed to fall to 1.3. The severe protein $\mathrm{C}$ deficiency was corrected by the use of intravenous protein

1 British Committee for Standards in Haematology. Guidelines on oral anticoagulation, 3rd edn. $\mathrm{Br} \mathcal{F}$ Haemato 1998;101:374-487.

2 Golino A, Crawford EM, Gathe JC, Dekmezian RH. Recurrent small bowel infarction associated with antithrombin deficency. Am ₹ Gastroenterol 1997;92:323-4.

3 Heresbach D, Pagenault M, Gueret P, et al. Factor V Leiden mutation in four patients with small bowel infarctions. Gastroenterology 1997;113:322-5.

4 Poort S, Rosendahl E, Reitsma P and Bertina R. A common genetic variation in the 3'-untranslated region of the prothrombin gene is associated with elevated prothrombin levels and an increase in venous thrombosis. Blood 1996;88:3698-703.

5 Makris M, Preston FE, Beauchamp NJ, et al. Coinheritance Makris M, Preston FE, Beauchamp NJ, et al. Coinheritance
of the 20210A allele of the prothrombin gene increases the of the 20210A allele of the prothrombin gene increases the
risk of thrombosis in subjects with familial thrombophilia. Thromb Haemostasis 1997;78:1426-9.

\section{Summary points}

- inherited thrombophilia has an incidence of at least $5 \%$ in the general population

- combined defects are being increasingly recognised and associated with an increased relative risk of venous thromboembolic disease

- thrombophilic screening should be undertaken in patients presenting with mesenteric venous infarction

- protein $\mathrm{C}$ concentrate is available and should be considered for congenitally deficient patients presenting with major venous thromboembolic complications

C concentrate. Prior to the commercial availability of protein $\mathrm{C}$ concentrate, fresh frozen plasma was traditionally used to raise protein C levels in cases of both inherited and acquired deficiencies with variable but generally poor therapeutic results. ${ }^{6}$

Intravenous protein $\mathrm{C}$ concentrate has been successfully used in cases of purpura fulminans in congenital homozygous deficient neonates ${ }^{7}$ and during pregnancy in a patient with a history of previous venous thrombosis and foetal $\operatorname{loss}^{8}$ with successful outcomes. Our case is the first to use protein $\mathrm{C}$ concentrate successfully in the context of established massive MVT and it is noteworthy that there were no postoperative thromboembolic problems. In the three years since his bowel resection he has had no further thrombotic events whilst on long-term warfarin. In addition to screening patients with MVT for thrombophilia, ${ }^{9}$ we feel protein C concentrate should be considered in congenitally deficient patients with major venous thromboembolic complications.

6 Gordon BG, Haire WD, Patton DF, Manno PJ, Reed EC. Thrombotic complications of BMT. Bone Marrow Transplant 1993;11:61-5.

7 Minford AMB, Parapia LA, Stainforth C, Lee D. Treatment of homozygous protein $\mathrm{C}$ deficiency with subcutaneous protein C concentrate. Br F Haematol 1997;93:215-6.

8 Richards EM, Makris M, Preston FE. The successful use of protein C concentrate during pregnancy in a patient with type 1 protein $C$ deficiency, previous thrombosis and recurrent foetal loss. Br F Haematol 1997;98:660-1.

9 British Committee for Standards in Haematology. Guidelines on the investigation and management of thrombophilia. F Clin Pathol 1990;43:703-9. 